\title{
AMENDMENTS
}

\section{Retraction Note: Tree growth in sync}

Lara M. Kueppers (1)

Retraction to: Nature Ecology \& Evolution https://doi.org/10.1038/s41559-020-01326-7, published online 26 October 2020.

In view of the fact that the authors of 'Evidence of unprecedented rise in growth synchrony from global tree ring records' (R. D. Manzanedo et al. Nat. Ecol. Evol.4, 1622-1629; 2020) are retracting their Article, Lara M. Kueppers is retracting this News \& Views, which dealt with the study and was based on the accuracy and reproducibility of the data in the paper.

Published online: 18 May 2021

https://doi.org/10.1038/s41559-021-01476-2

๑) Springer Nature Limited 2021 